\title{
Mediastinal carcinoid tumour with unusual manifestations
}

\author{
Praveen Aggarwal ${ }^{1}$, Surender Kumar Sharma ${ }^{1}$, Tushar Kanti Chattopadhyay ${ }^{2}$ and \\ Ashok Kumar Mukhopadhyay ${ }^{3}$
}

Departments of ${ }^{1}$ Medicine, ${ }^{2}$ Surgery and ${ }^{3}$ Pathology, All India Institute of Medical Sciences, New Delhi 110029, India.

\begin{abstract}
Summary: A rare case of mediastinal carcinoid tumour with superior vena cava obstruction, and osteolytic as well as osteoblastic secondaries in the bones is described. The relevant literature is reviewed.
\end{abstract}

\section{Introduction}

Carcinoid tumours occur most commonly in the gastrointestinal tract. Other reported sites include the lung, gall bladder and bile duct, parotid, pancreas, ovary, cervix and testis. In recent years, similar tumours occurring in the anterior mediastinum have been described.' In this report, we describe certain unusual features in a patient with mediastinal carcinoid.

\section{Case report}

A 36 year old male presented with pain in the right arm radiating along its medial aspect, of 3 years duration, worse on coughing and sneezing. One year before admission he noticed progressive thinning of the right leg. At about the same time, he also developed sudden nasal regurgitation, slurring of voice and deviation of tongue to the left side and these symptoms persisted at the time of admission. Six months prior to admission, he noticed facial puffiness along with mild dyspnoea on exertion. He had lost $12 \mathrm{~kg}$ in weight in the past year.

Examination revealed signs of superior vena cava obstruction. Chest examination revealed dullness in the right upper parasternal area. The nervous system examination showed evidence of lower motor neurone palsies of IX, X and XII cranial nerves on the left side along with slight wasting of the right calf muscles and decreased sensation along $D_{1}$ distribution in the right arm. The ankle jerk on the right side was absent.

The chest $\mathrm{X}$-ray showed a superior mediastinal mass (Figure 1). The skeletal survey showed multiple lytic lesions in the $\mathrm{D}_{4}, \mathrm{D}_{5}$ and $\mathrm{L}_{4}$ vertebrae; multiple areas of sclerosis in the pelvis and upper femora and multiple lytic lesions in the skull (Figure 2). There was no

Correspondence: Surender K. Sharma, M.D.

Accepted: 19 October 1988
M-spike in the blood or Bence-Jones protein in the urine. An ultrasonography of the abdomen and computed tomography of the skull were normal. Repeated attempts to obtain tissue by needle aspiration of the mediastinal mass were unsuccessful.

At thoracotomy, a large mass occupying the superior mediastinum with infiltration of the great vessels was found. Histopathology of a biopsy revealed groups of small, rounded cells, separated by dilated vascular endothelial channels. The cells had scant cytoplasm and darkly-stained nuclei, occupying almost the whole of the cells. The cytoplasm contained

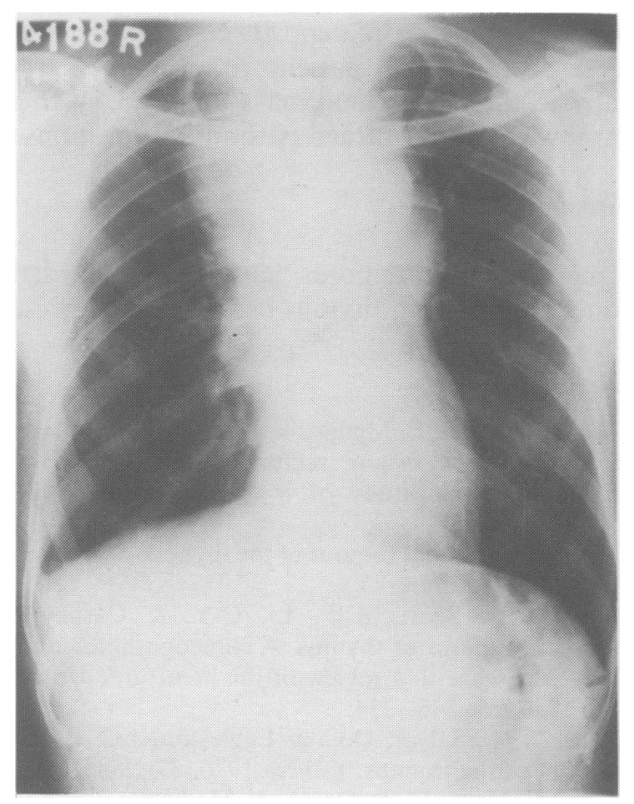

Figure 1 Chest X-ray showing a superior mediastinal mass.

(C) The Fellowship of Postgraduate Medicine, 1989 


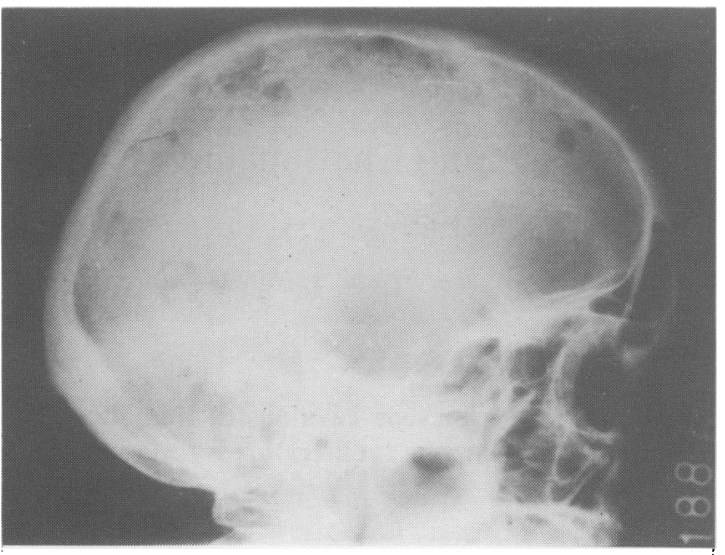

Figure 2 Skull X-ray showing multiple lytic lesions.

fine granules. Numerous mitotic figures were seen. The appearances were compatible with carcinoid tumour.

In a search for carcinoid tumour elsewhere, radiographic evaluation of the gastrointestinal tract and a fibreoptic bronchoscopy were performed. There was no evidence of tumour at both these sites. Twenty-four hour urinary 5 -hydroxyindoleacetic acid $[2.2 \mathrm{mg}$ (normal 2-8 mg)] and 17-hydroxysteroid [6 mg (normal $2-10 \mathrm{mg})]$, and plasma cortisol levels were not elevated.

A final diagnosis of malignant carcinoid tumour of the mediastinum with superior vena cava obstruction and multiple osteolytic and osteoblastic secondaries was made. The neurological involyement was thought to be due to metastatic deposits causing pressure on the nerve roots. The patient received local radiotherapy to the mediastinal mass followed by chemotherapy with 5-fluorouracil without any response.

\section{Discussion}

The mediastinal carcinoids have been regarded as tumours arising from thymus because of the presence

\section{References}

1. Rosai, J. \& Higa, E. Mediastinal endocrine neoplasm, of probable thymic origin, related to carcinoid tumour. Clinicopathologic study of 8 cases. Cancer 1972, 29: $1061-1074$.

2. Kogan, J. Carcinoid tumour of the thymus. Postgrad Med 1984, 75: 291-296.

3. Wick, M.R., Scott, R.E., Li, C-Y. \& Carney, J.A. Carcinoid tumour of thymus. A clinicopathologic report of seven cases with a review of the literature. Mayo Clin Proc 1980, 55: 246-254.

4. Salyer, W.R., Salyer, D.C. \& Eggleston, J.C. Carcinoid tumours of the thymus. Cancer 1976, 37: 958-973.

5. Rosai, J., Higa, E. \& Davie, J. Mediastinal endocrine neoplasm in patients with multiple endocrine adenomatosis. A previously unrecognized association. Cancer 1972, 29: 1075-1083. of Kulchitsky's cells (the origin of these tumours) thymus and also because of the demonstration af remnants of thymic tissue in many of these tumous. Fewer than 100 cases of thymic carcinoids have been reported. ${ }^{2}$ The male/female incidence is $3: 1$ and the tumours present most commonly in the fourth a $\overrightarrow{\mathrm{B}}$ fifth decades of life.

The symptoms are nonspecific and consist of dys noea, cough and chest pain. ${ }^{1}$ Out of the 8 casess reported by Rosai and Higa, ${ }^{1} 5$ were asymptomati. Wick et $a .^{3}$ reported 7 cases, of which two had superior vena cava obstruction. Out of 3 cases reported by Salyer et al. $^{4}$ two patients developed superior obstruction during follow up. Carcinoid tumours of the thymus have also been reported to associated with multiple endocrine adenomatosis ${ }^{5}$ and with Cushing's syndrome. ${ }^{3,4}$ Systemic features in the form of polyarthritis and paraesthesiae, weight los,; clubbing, hepatomegaly and proximal myopathy hase also been reported. ${ }^{6}$ Carcinoid syndrome has not yot been described in any patient with thymic carcinoig tumours.

In patients with malignant carcinoid tumours, the metastatic bone deposits are mostly osteoblastic while osteolytic lesions are rare. ${ }^{8}$ Osteolytic as well osteoblastic lesions in the same patient have bein reported rarely. ${ }^{9}$ To our knowledge, osteolytic metas tatic bone lesions have not been previously reported of thymic carcinoids.

The primary mode of therapy in thymic carcin surgical removal. In a review of 16 cases, ${ }^{1}$ the vişb tumour could be removed in 12 patients out of whom were alive for 1-9 years postoperatively. The response to radiotherapy is poor. ${ }^{1}$

The present case is of interest not only because of the location of the tumour but also because of the presen£ of the superior mediastinal obstruction and the osteolytic as well as the osteoblastic secondaries in the bones. The possibility of thymic carcinoid, although quite rare, should be considered in the differentiol diagnosis of tumours in this location.

6. Lowenthal, R.M., Gumpel, J.M., Kreel, L., McLaughlißુ, J.E. \& Skeggs, D.B.L. Carcinoid tumour of the thymus with systemic manifestations: a radiological and pathological study. Thorax 1974, 29: 553-558.

7. Thomas, B.M. Three unusual carcinoid tumours, with particular reference to osteoblastic bone metastases. $C$ in Radiol 1968, 19: 221-225.

8. Bichile, L.S., Pandit, S.P., Kuloor, P.L., Abhyankar, S.థ̛ Hedge, A. \& Nanivadekar, S.A. Carcinoid tumour of lumg with haemorrhagic pleural effusion and extensive metastasis. Indian J Chest Dis Allied Sci 1984, 26: 51-53.

9. Norman, A., Greenspan, A.\& Steiner, G. Case report 17 電: Varified osteolytic metastasis in the clavicle from $\frac{T}{a}$ bronchial carcinoid tumour and probable osteoblastile metastasis in the humerus from the same lesion. Skelet Radiol 1981, 7: 155-157. 